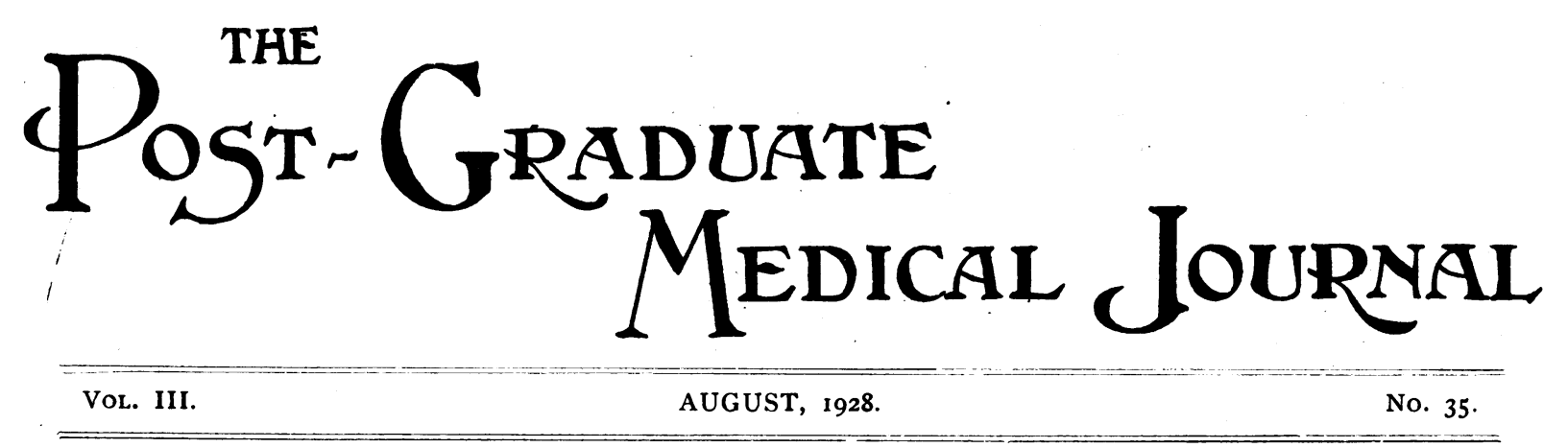

\title{
CONTENTS
}

The Rôle of the Sanatorium in the Treatment of Pulmonary $\begin{array}{lllllllllll}\text { TUBERCUlOSIS } & \ldots & \ldots & \ldots & \ldots & \ldots & \ldots & \ldots & \ldots & \ldots & 193\end{array}$

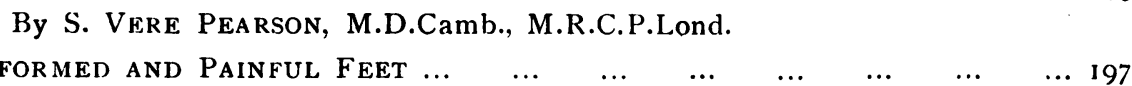
Deformed and Painful Feet $\ldots$...
By A. S. Blundell Bankart, F.R.C.S.

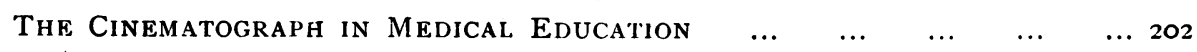

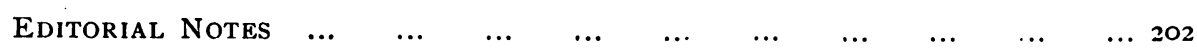

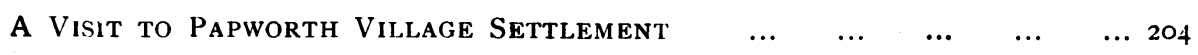

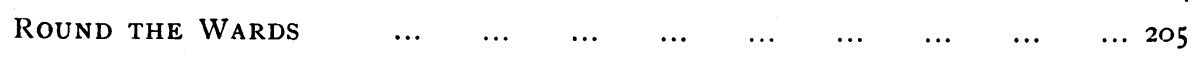

$\begin{array}{lllllllllll}\text { Post-Graduate News } & \ldots & \ldots & \ldots & \ldots & \ldots & \ldots & \ldots & \ldots & \ldots & 205\end{array}$

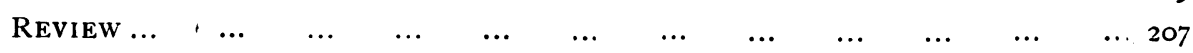

CORRESPONDENCE

Fellowship of Medicine and Post-Graduate Medical Association.-

$\begin{array}{llllllllll}\text { SPECIAL COURSES } \ldots & \ldots & \ldots & \ldots & \ldots & \ldots & \ldots & \ldots & \ldots & \text { iv }\end{array}$

THE

RÔLE OF 'THE SANATORIUM

IN THE

\section{TREATMENT OF PULMONARY TUBERCULOSIS.}

\section{By S. VERE PEARSON,}

M.D.CAMB., M.R.C.P.LOND.

Resident Physician, Mundesley Sanatorium.

IN order properly to assess the role of the sanatorium in the treatment of pulmonary tuberculosis it is well first of all to set out what constitutes sanatorium treatment. The essential features of sanatorium treatment are : firstly, the close and skilled supervision in good surroundings of the remedial- measures used; secondly, the proper training of the individual in hygienic living, particularly in respect to breathing fresh air, taking adequate rest, feeding rationally and preventing infection. Resort to a sanatorium, too, frequently includes the removal of the patient from those deleterious influences and conditions of his home which are only too common. Also in considering the rôle of a sanatorium, emphasis must be laid upon its educational influence on others than the patient, which education helps to prevent the disease.

In the last two decades considerable advances have been made in the treatment of pulmonary tuberculosis. Not only has the principle of graduated rest come to be better understood, and the dieting of patients and the management of exposure to 
fresh air been put on a more rational basis, but also it has been found possible to restore to health by means of artificial pneumothorax treatment and its concomitants a better proportion of those with advanced disease than was formerly the case. The management of a case of artificial pneumothorax, although the principles of the treatment are fairly simple, requires experience and close watching of the patient. The chances of getting good results by this procedure are enhanced very much by residence in an institution for certain periods, at all events during the more critical stages of the treatment. Then it is easy to watch all the symptoms as well as to observe on the X-ray screen, or film if necessary, the signs in the chest and check the treatment accordingly. Furthermore, when an effective compression by means of artificial pneumothorax treatment is found to be impossible or inadvisable, it is in a sanatorium that that experience is to be found and those observations can most readily be made which are necessary adjuncts to the forming of a sound judgment as to how best to proceed in order to give the patient the best chances of recovery. Some of these are able to receive great benefit by rather drastic and difficult surgical procedures. It is a pity in the interests of these patients that these operations cannot always be done in a sanatorium for there they should be in the best physical surroundings and in a place where their medical and nursing requirements are best attended to. If a thoracoplasty has to be done in a city, especially in winter-time, a smoky fog may descend inopportunely and seriously jeopardize the patient's welfare. But, unfortunately, too seldom is the sanatorium superintendent a skilled surgeon, and it is not always easy to arrange the adequate sojourn within the sanatorium of a surgeon thoroughly experienced in and clever at these operations. The treatment during anæsthetization, immediately after the operation, as well as the nursing of the patient for many days after it, should all be in experienced hands.

Then again there is the more recent treatment of pulmonary tuberculosis by the intravenous injection of gold salts. In this case too, judgment and experience are required, not only in the choice of patients for whom this form of treatment should be tried, but also in the dosage and administration of the drug. In former days the allimportant supervision of rest and exercise, and to a less extent of the fresh air and feeding, was looked upon as the chief function of the sanatorium physician. Today, while these remain of paramount importance, there are these other measures requiring special knowledge and experience which are very helpful for certain patients.

It is still too common to find a woeful ignorance regarding the necessity for resting in the active stages of pulmonary tuberculosis. I have known many patients whose chances of making a satisfactory and moderately quick recovery have been spoilt or even ruined by ignorance in this direction. People are often told that they are not sufficiently ill to necessitate residence in a sanatorium; that home treatment will put matters right. And many very readily acquiesce in this advice because they have a curious idea of what life within a sanatorium is like, and because anxious relatives will not steel themselves to sacrifice their feelings and refuse to hand over their dear ones to expert doctors and nurses in a strange place. The fault sometimes undoubtedly lies with the sanatorium, though as a rule these partake not at all either of a prison or an asylum. Now, unfortunately, the use of careful-preferably rectal-temperature readings and the ordaining of rest when even slight degrees of fever are present is not taught to students and practitioners. Consequently patients with pulmonary tuberculosis which is slightly active are allowed to go about, are indeed quite often encouraged for the sake of obtaining an abundance of fresh air to exercise themselves in the open air, when they may be 
thereby jeopardizing their chances of making a good recovery in a reasonable time. Two of the commonest contributory factors which turn the scale against or hasten the end of sufferers from pulmonary tuberculosis are over-exertion, and over-anxious, fussy, and interfering relatives. Amongst the deleterious influences of homes that is sometimes one. It is often difficult for relations to learn not to coddle the patient too much, and to leave him alone to work out his own salvation. With the idea of keeping a bed-resting patient's spirits up relatives and friends sometimes talk with him or her for hours a day, to the patient's hurt. But undoubtedly the commonest defects and drawbacks of home conditions are those due to poverty. Inadequate financial resources of masses of the people are especially apt to hit an invalid. Furthermore a majority of people, about 75 per cent. for example in England and Australia, have the misfortune to live in cities which are smoky and in other particulars not so hygienic as they might be. These defects of environ. ment are among the reasons why patients developing pulmonary tuberculosis seek residence in a sanatorium. Dr. Claude Lillingston well wrote in the Lancet (1923, vol. i), in discussing "The Treatment of Early Pulmonary Tuberculosis in the Young Adult": "The patient who has just developed pulmonary tuberculosis must completely revolutionize his life if he wants it to be long. He must be born again. Only in a well-conducted sanatorium is his rebirth feasible. He has to learn how to regulate every hour of his day, what to do and, above all, what not to do. In the sanatorium he learns from second- and third-stage patients how they came to this pass. Re-admission patients tell him the story of their relapse-how it might have been avoided. All this much and more he learns at the sanatorium. To expect him to acquire this knowledge from books and casual chats with his medical attendant is to expect the impossible."

The Departmental Committee on Tuber- culosis appointed in I9 I I, with Waldorf Astor in the Chair, envisaged sanatoriums as places where those patients who would probably prove curable were to be domiciled, while hospital accommodation was to be set aside for the advanced cases. This ideal has never been able to be reached properly because of the nature of pulmonary tuberculosis, and also because of the difficulty of reaching an early diagnosis. Dr. Lissant Cox points out in his report for the Lancashire County Council for the year 1926 that nearly threequarters of the patients referred to his officers had been feeling ill for a month or more before consulting any doctor. He has made careful investigations during the last few years as to the causes of the delay in consultations. He feels sure that it in many instances due to ignorance, economic reasons, and the insidious onset of the disease. In his county there is not an unreasonable delay in patients being referred by their practitioners to the tuberculosis officers. But in some counties there is delay in this last action owing to lack of confidence on the part of general practitioners in the specialist knowledge of the tuberculosis officer. The post of tuberculosis officer is too often a blind alley; it is paid too low a salary; consequently good, experienced men are not always to be found filling these posts. Similarly, and partly because the tuberculosis services are now so much public services, in many parts of the country specialist consultants with sound experience in the diagnosis and treatment of pulmonary tuberculosis are hard to find. The diagnosis is not made early enough, the best use of sanatoriums is not made because too much reliance is placed upon physical examination of the chest, and too little upon an examination of sputum and a study of symptoms. The average general practitioner has yet to learn that pulmonary tuberculosis may be present and active, for example, after a slight hæmoptysis, though he can discover no abnormal signs in the chest, even in fact when an expert chest physician or chest 
radiologist is unable to be sure of its location. And even otherwise skilled physicians will sometimes venture from physical examination of the chest to pronounce that the perhaps extensive disease they find is healed and inactive, and advise against residence in a sanatorium. A short period of observation in a sanatorium will more easily decide this possibly at times very difficult question even if the chest were never examined.

One of the rôles which sanatoriums should fill much more than they do to-day is : they should be used for the education of medical practitioners and students, and as places for research. As long ago as 1912 the Astor Committee at the conclusion of their first report gave it as their final recommendation :-

"That inasmuci as the opportunities which are now afforded in general hospitals to students of medicine for the ohservation of the course and treatment of tuberculosis are insulficient to secure provision of an adequate number of expert medical officers, advantage should be taken of the extended opportunities which will be afforded under the proposed scheme to obtain additional instruction."

In the sixteen years which have elapsed since that report was issued, it is sad to relate that that recommendation has been acted upon only to a small extent.

The results obtained from adequate residence in a sanatorium, are undoubtedly better when contrasted with the results obtained in the case of patients treated under other conditions. For example, Dr. Lissant Cox in his I ancashire County Council Report for I926 (p. 99) says that " Contrasted with the 2,00o patients who did not for some reason go to a sanatorium, those who received institutional treatment invariably did better in after-life, the difference in their favour differing from 20 per cent. to nearly 300 per cent. according to the type of case." Again, to refer to the period of residence being adequate, a comparison of the results of handling those of the 18,000 employees of the Metropolitan Life Assurance Company of New York, who contract tuberculosis, with most other results, shows that through earlier diagnosis, somewhat longer periods of treatment in sanatoriums and better after-care, but probably especially through longer stay in a special residential institution, the percentage of cures is more than 50 per cent higher than that which obtains in England (see Lancet, 1923, i, p. 250).

A patient discharged from a sanatorium has a big influence upon the personal hygienic habits and the conditions of those around him. This helps the prevention of the disease. The factors causing tuberculosis which are most rife are : the frequent absence of clean air, especially in bedrooms and workrooms, the presence of tubercle bacillus, the poor means for ensuring an early diagnosis of the disease, and certain social and industrial conditions affecting the food and work of the individual.

To-day, partly due to the past influence of sanatoriums, there is not, at all events in England, the same necessity for preaching the advantages of clean arr in dwelling houses as there used to be. But those who have learned the advantages of pure fresh air through residence in a sanatorium are certainly keener than the majority of people in advocating smoke abatement, garden cities, and the design of public buildings so that they are better ventilated than is commonly the case to-day.

Regarding the spread of the tubercle bacillus; it is not the man who comes from a o well-conducted sanaturium who is generally $\tilde{N}$ to be feared as a source of infection. He $\mathrm{\omega}$ not only knows and practises what precautions are necessary, but he also enlightens others. On the other haind, the untrained $\stackrel{\mathbb{Q}}{+}$ man in bad surroundings, often suffering 0 from consumption which is undiagnosed, $\stackrel{\circ}{\mathbb{D}}$ without knowledge of the evils of his sur- $\frac{\stackrel{\rho}{\mathbb{D}}}{\mathbb{D}}$ roundings or desire for their betterment, $\frac{\mathbb{Q}}{0}$ may be disseminating the disease broadcast.

Again, sanatoriums have a powerful in- 
fluence upon the spread of knowledge as to the necessity of the early diagnosis of consumption and as to how best to ensure this. The ex-sanatorium patient sometimes more readily than the practitioner helps others to realize the importance of early symptoms, of the examination of expectoration and of complete rest when slight fever is present.

\section{DEFORMED AND PAINFUL FEET.}

\section{By A. S. BLUNDELL BANKART, \\ F.R.C.s.}

Surgeon, Royal National Orthopadic Hospital ; Orthopadic Surgeon, Middlesex Hospital.

IF we accept the conventional view of a normal foot, as a structure built in the form of an arch, which at all costs must be maintained at or above a certain height, then undoubtedly the commonest painful deformities of the foot are: (I) Those in which the arch is too low, and (2) those in which it is too high, namely, flat foot and pes cavus respectively.

Whether we accept this conventional view or not, is a question to which I shall refer immediately.

The normal foot is described as having a longitudinal arch, that is to say, its inner border is raised in the form of an arch which gradually slopes away to the outer side, so that in standing the foot rests, on the heel, the outer border, and the heads of the metatarsal bones.

It is commonly thought that this arch is maintained at least to some extent by the ligaments and fasciæ in the sole of the foot, and that when these give way the patient suffers from flat foot.

The height of the arch varies in different individuals, and no one can say precisely where a low arch ends and flat foot begins, nor where a high arch becomes pes cavus.
Nowadays, however, it is more generally recognized that the actual height of the arch is of comparatively little importance, and that mobility and muscular control of the foot are the essential features. I would go further, and say that the ideal foot should have no arch at all in an anatomical sense; it should be so supple that it can be completely flattened, or raised in the form of an arch, at will, and its muscles should be capable of maintaining its correct attitude in all circumstances.

The correct attitude of the foot in standing is a part of the postural reflex which maintains the upright position of the body as a whole against gravity. The body-weight is borne by the postural muscles which prevent excessive abduction and eversion of the foot. It is not the function of any ligaments to withstand continuous strain ; this is always a function of muscles.

So that the position in which the foot assumes an arch is an attitude maintained by muscular activity, and it is maintained only so long as the muscles are in action. When they relax, the arch becomes flattened, and, if the foot is sufficiently supple, it becomes quite flat when standing at ease. Such a condition is seen normally in the feet of bare-footed races who have never worn boots or shoes, in the feet of the best ballet dancers, and commonly in children who are learning to walk. Their feet are quite flat when standing at ease, but, nevertheless, they are quite normal and efficient in use.

Unfortunately, in the majority of civilized people who wear boots and shoes, the range of movement at the tarsal joints becomes restricted, and by contracture or adaptation (call it what you will) of the soft parts in the sole, the arch of the foot becomes more or less fixed, so that it cannot be flattened without meeting the resistance of these shortened structures. Consequently, the individual is compelled to keep the arch of his foot always above a certain height, for otherwise the weight of his body will fall upon these shortened structures and will 